\title{
Surgical treatment of patients with coronary heart disease and mild stenosis of the aortic valve
}

\author{
Anatoly Molochkov ${ }^{1}$, Igor Zhbanov ${ }^{1}$, Boris Shabalkin', Vadim Domnin ${ }^{1}$
}

${ }^{1)}$ Clinic Of Heart Surgery, Petrovskiy National Research Centre Of Surgery, Moscow, Russia

\section{Summary}

Objective: Management of asymptomatic mild aortic stenosis at the time of coronary artery bypass grafting remains controversial. Therefore we have reviewed our experience with such patients.

Material and Method: We have retrospectively analyzed a cohort of 42 patients (group A) with asymptomatic aortic valve lesion subjected to isolated coronary artery bypass (38 men and 4 women with a mean age of $56.4 \pm 6.5$ years) and compared their with a group of 67 patients (group B) receiving coronary artery bypass grafting and aortic valve replacement simultaneously at the first operation (61 men and 6 women with a mean age of $63.4 \pm 7.3$ years). No significant differences in the characteristics of patients in both groups were noted.

Results: Acute heart failure, perioperative myocardial infarction, heart arrhythmia, respiratory failure, most often observed among patients of group B. Hospital mortality among these patients was also higher $(6.3 \%$ versus $0, p>0.05)$. However, these differences were not significant. $11(26.1 \%)$ patients, who had undergone CABG an average of 30.6 \pm 13.3 months previously, were subsequently re-operated due to progression of aortic stenosis. We noted that mean preoperative aortic gradient $(34.8 \pm 4.4$ versus $26.3 \pm 7.5 \mathrm{~mm}$. $\mathrm{Hg} \mathrm{p}<0.05)$ and calcification of the aortic valve $(1.6 \pm 0.5$ versus $0.8 \pm 0.7 p<0.05)$ in these patients was significantly higher than the remaining patients of group A. Progression of valvar calcification has led to a decrease in the area of the aortic opening an average of $0.25 \pm 0.04 \mathrm{~cm}^{2} /$ year and an increase in the gradient, an average of $13.3 \pm 9.3 \mathrm{~mm} . \mathrm{Hg} /$ year.

Conclusion: Thereby, calcification of the aortic valve with mild to moderate aortic stenosis and a mean pressure gradient within $25-40 \mathrm{~mm}$ $\mathrm{Hg}$ is sufficient to carry out combined operations. Execution only isolated coronary artery bypass grafting determines the greater likelihood of re-operation because of the inevitable progression of aortic valve calcification.

Keywords: Aortic valve disease, coronary bypass surgery, aortic stenosis. 


\section{Introduction}

The combined atherosclerotic lesion of coronary arteries and aortic valve is a typical and common condition especially among elderly patients. Management of asymptomatic mild aortic stenosis at the time of coronary artery bypass grafting remains controversial. Some surgeons advocate aortic valve replacement (AVR) on the assumption that many of these patients will develop significant valve disease within a few years time. ${ }^{(1)}$

Thus they would otherwise be exposed to the risks of a redo operation to replace the valve. On the other hand, critics of this position believe that prophylactic AVR for mild aortic stenosis in a patient whose primary symptoms are coronary insufficiency unjustifiably increases the operative mortality as well as the risk of subsequent valve-related events, and such patients should not have valve replacement until hemodynamically significant aortic stenosis develops. ${ }^{(3)}$ Therefore we have reviewed our experience with such patients.

\section{Materials and methods}

We have retrospectively analyzed a cohort of 42 patients (group A) with asymptomatic aortic valve (AV) lesion subjected to isolated coronary artery bypass (38 men and 4 women with a mean age of $56.4 \pm 6.5$ years) and compared their with a group of 67 patients (group B) receiving coronary artery bypass grafting and aortic valve replacement simultaneously at the first operation (61 men and 6 women with a mean age of $63.4 \pm 7.3$ years). New York Heart Association (NYHA) functional class, history of myocardial infarction, prior operation was recorded. Angina was graded using the Canadian Cardiovascular Society (CCS) classification.

Cardiac catheterization findings recorded included number of diseased vessels and left ventricular (LV) function. LV end-diastolic pressure, state of the $\mathrm{AV}$ and systolic gradient across the $\mathrm{AV}$ at first and subsequent catheterizations were also recorded. Aortic stenosis was considered mild when the aortic valve area was $1.0 \mathrm{~cm}^{2}$ or greater, moderate when the area was less than 1.0 $\mathrm{cm}^{2}$ but greater than $0.7 \mathrm{~cm}^{2}$, and severe when the area was $0.7 \mathrm{~cm}^{2}$ or less. Progression of aortic stenosis was considered to have occurred after stenosis increased from mild to moderate, mild to severe, or moderate to severe on the basis of the calculated aortic valve area.

The general conduct of all surgical procedures was similar. The operations were performed using a membrane oxygenator, systemic normothermia $\left(34-36^{\circ} \mathrm{C}\right)$, hemodilution and cardioplegic solution.

\section{Results}

Both groups were similar with respect to the risk factors for heart disease. The extent of coronary artery disease and the frequency of preoperative myocardial infarction were similar. The majority of patients in both cohorts had mild left ventricular dysfunction. No significant differences in the characteristics of patients in both groups were noted (Table 1).

\section{Table 1. Patient characteristics}

\begin{tabular}{|l|c|c|c|}
\hline \multicolumn{1}{|c|}{ Variable } & Group A (n-42) & Group B (n-67) & p Value \\
\hline Angina class (CCS): & & & \\
\hline III & $(83.4 \%)$ & $54(80.5 \%)$ & NS \\
IY & $7(17.1 \%)$ & $13(19.4 \%)$ & \\
\hline NYHA class: & $5(11.9 \%)$ & $7(10.4 \%)$ & NS \\
\hline II & $28(66.7 \%)$ & $49(73.1 \%)$ & \\
\hline III & $9(21.4 \%)$ & $11(16.2 \%)$ & NS \\
\hline IY & $19(45.2 \%)$ & $34(50.1 \%)$ & NS \\
\hline Myocardial infarction & $17(40.4 \%)$ & $31(46.2 \%)$ & NS \\
\hline Ejection Fraction < 0.5 & $23(54.7 \%)$ & $38(56.7 \%)$ & \\
\hline Triple and more Coronary lesion & CCS $=$ Canadian Cardiovascular Society. \\
\hline NYHA = New York Heart Association; &
\end{tabular}


Table 2. Cardiac catheterization data

\begin{tabular}{|l|c|c|c|}
\hline Variable & Group A $(\mathrm{n}-42)$ & Group B (n-67) & p Value \\
\hline Mean AV gradient (mm Hg) & $28.4 \pm 8.1$ & $56.2 \pm 11.7$ & $<0.05$ \\
\hline Aortic valve area (cm2) & $1.5 \pm 0.4$ & $0.7 \pm 0.3$ & $<0.05$ \\
\hline Aortic valve regurgitation & $0.9 \pm 0.5$ & $2.1 \pm 1.3$ & $<0.05$ \\
\hline LVEDP (mm Hg) & $10.8 \pm 2.6$ & $17.5 \pm 8.5$ & $<0.05$ \\
\hline Calcification of the AV & $0.9 \pm 0.8$ & $1.7 \pm 0.7$ & $<0.05$ \\
\hline \multicolumn{2}{|c|}{$A V=$ aortic valve. } \\
\hline
\end{tabular}

None of the patients in group A were considered to have hemodynamically significant aortic stenosis at the time of the initial myocardial revascularization. Patients of group B had a significant stenosis and calcification of the aortic valve (Table 2).

In both groups the use of internal mammary artery (IMA) and the number of bypass grafts inserted were similar. Patients in group B were undergoing combined (CABG and AVR) procedures and not unexpectedly incurred a significantly greater global myocardial ischemic and extracorporeal circulation time (Table 3).

Postoperative complications occurred with a significantly greater frequency in those patients having AVR and myocardial revascularization. The most frequent postoperative complications were acute heart failure, perioperative myocardial infarction, heart arrhythmia, (Table 4). Hospital mortality among these patients was also higher. There were 4 patients (group A - 0; group B - 5.9\%; not significant) who died in the hospital.
The most common cause of death was low cardiac output. $(n-2)$. The remaining 2 hospital deaths were caused by multiorgan system failure (n-1) and cerebrovascular accident (n-1). Five-year survival in both groups was similar (Fig.3).

\section{Figure 3. Survival}

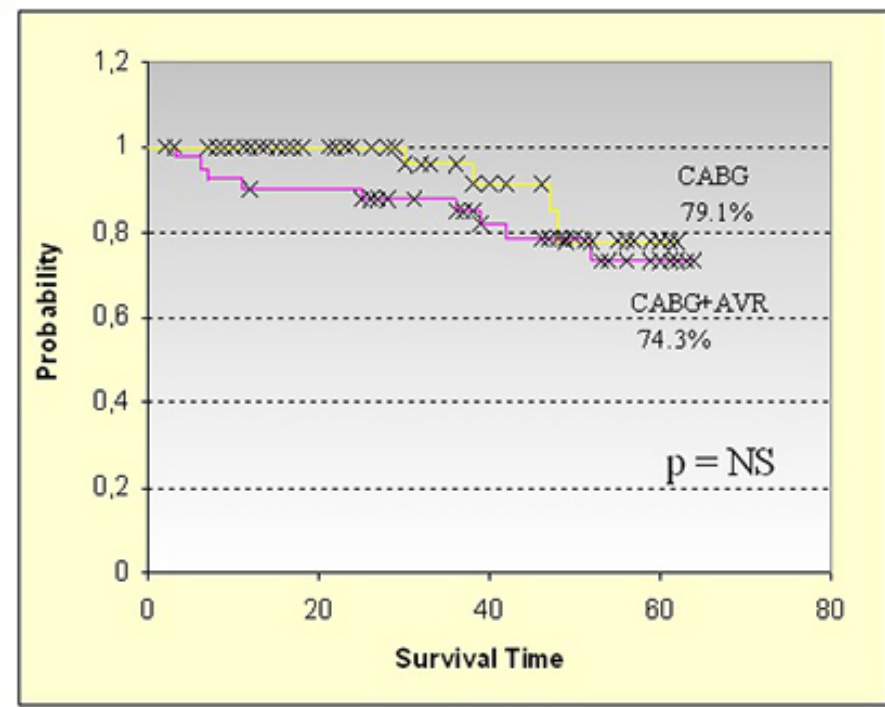

Table 3. Operative data

\begin{tabular}{|l|c|c|c|}
\hline Variable & Group A (n-42) & Group B (n-67) & p Value \\
\hline IMA & $40(95.2 \%)$ & $61(91.1 \%)$ & NS \\
\hline No. of CAB grafts & $3.2 \pm 1.1$ & $2.8 \pm 0.8$ & NS \\
\hline CPB time $(\min )$ & $79 \pm 26.4$ & $147 \pm 31.2$ & $<0.05$ \\
\hline Cross-clamp time $(\min )$ & $40.2 \pm 18.8$ & $98 \pm 22.3$ & $<0.05$ \\
\hline CAB = coronary artery bypass; CPB = cardiopulmonary bypass; IMA = Internal mammary artery NS = not significant. \\
\hline
\end{tabular}


Table 4. Postoperative complications

\begin{tabular}{|l|c|c|c|}
\hline Variable & Group A (n-42) & Group B (n-67) & p Value \\
\hline Acute cardiac failure & $3(7.1 \%)$ & $11(16.4 \%)$ & NS \\
\hline Arrhythmia & $5(11.9 \%)$ & $19(28.3 \%)$ & $<0.05$ \\
\hline Myocardial infarction & $2(4.7 \%)$ & $4(5.9 \%)$ & NS \\
\hline Stroke & - & $1(1.4 \%)$ & NS \\
\hline Postoperative bleeding & - & $5(7.4 \%)$ & NS \\
\hline Mortality & - & $4(5.9 \%)$ & NS \\
\hline
\end{tabular}

\section{Discussion}

We emphasize that our review does not provide information on the incidence of need for subsequent valve replacement in the category under consideration, ie, concomitant mild aortic stenosis and coronary artery disease requiring reoperation. Our review does confirm that in at least a portion of such cases, the valve stenosis progresses and reoperation causes a burden of increased risk.

This observation has been reported by Collins and associates. According to their research appearance of symptoms and signs of severe AS occurred in $16 \%$ by 3 years; $45 \%$ by 4 years; and $75 \%$ by 5 years after CABG surgery. They demonstrated a $23.5 \%$ operative mortality for reoperative AVR after CABG compared with $7.6 \%$ for reoperative AVR without $\mathrm{CABG}$ and $6.6 \%$ for primary AVR with CABG. ${ }^{(2)}$ The reasons for this high mortality are multifactorial. At the time of reoperation the patients are older and the procedure takes longer.
Age, prolonged bypass time, and prolonged crossclamp time are the strongest independent predictors of mortality after AVR. ${ }^{(4,5)}$

Patients requiring AVR subsequent to $\mathrm{CABG}$ have progressive native and graft coronary atherosclerosis, which may need to be addressed at reoperation. ${ }^{(6)}$ $11(26.1 \%)$ patients in our study, who had undergone CABG an average of $30.6 \pm 13.3$ months previously, were subsequently re-operated due to progression of aortic stenosis. The average age was $66.8 \pm 5.2$ years. We analyzed the patients subjected to re-operation, and noted that mean preoperative aortic gradient $(34.8 \pm 4.4$ versus $26.3 \pm 7.5 \mathrm{~mm} . \mathrm{Hg} \mathrm{p}<0.05)$ and calcification of the aortic valve $(1.6 \pm 0.5$ versus $0.8 \pm 0.7 p<0.05)$ in these patients was significantly higher than the remaining patients of this group (Table 5).

Progression of valvar calcification has led to a decrease in the area of the aortic opening an average of $0.25 \pm 0.04 \mathrm{~cm}^{2} /$ year and an increase in the gradient, an

Table 5. Cardiac catheterization data re-operated and the remaining patients of Group A.

(before the first operation)

\begin{tabular}{|l|c|c|c|}
\hline Variable & $\begin{array}{c}\text { Re-operated } \\
\text { patients }(\mathrm{n}-11)\end{array}$ & $\begin{array}{r}\text { Non-operated } \\
\text { patients (n-31) }\end{array}$ & p Value \\
\hline Mean AV gradient (mm Hg) & $34.8 \pm 4.4$ & $26.3 \pm 7.5$ & $<0.05$ \\
\hline Aortic valve area (cm2) & $1.4 \pm 0.3$ & $1.6 \pm 0.2$ & NS \\
\hline Aortic valve regurgitation & $1.1 \pm 0.3$ & $0.9 \pm 0.4$ & NS \\
\hline LVEDP (mm Hg) & $12.3 \pm 2.3$ & $11.2 \pm 2.5$ & NS \\
\hline Calcification of the AV & $1.6 \pm 0.5$ & $0.8 \pm 0.7$ & $<0.05$ \\
\hline \multicolumn{2}{|c|}{ LVEDP = left ventricular end-diastolic pressure; AV= aortic valve } \\
\hline
\end{tabular}


Table 6. Dynamics of Cardiac Catheterization Data Re-operated Patients

\begin{tabular}{|l|c|c|c|}
\hline Variable & $\begin{array}{c}\text { before the first } \\
\text { operation }\end{array}$ & $\begin{array}{c}\text { before the sec- } \\
\text { ond operation }\end{array}$ & p Value \\
\hline Mean AV gradient (mm Hg) & $34.8 \pm 4.4$ & $68.2 \pm 22,9$ & $<0.05$ \\
\hline Aortic valve area (cm2) & $1.4 \pm 0.3$ & $0.8 \pm 0.2$ & $<0.05$ \\
\hline Aortic valve regurgitation & $1.1 \pm 0.3$ & $1.9 \pm 0.9$ & NS \\
\hline LVEDP (mm Hg) & $12.3 \pm 2.3$ & $17.1 \pm 7.6$ & $<0.05$ \\
\hline Calcification of the aortic valve & $1.6 \pm 0.5$ & $2.6 \pm 0.4$ & $<0.05$ \\
\hline \multicolumn{2}{|c|}{$L V E D P=$ left ventricular end-diastolic pressure. } & & \\
\hline
\end{tabular}

average of $13.3 \pm 9.3 \mathrm{~mm} . \mathrm{Hg} /$ year (Table 6). Changes in the aortic valve were atherosclerotic in nature, which manifested significant calcification valves and fibrous ring (Fig 1).

Main difficulties encountered during re-operation were: access to the heart, myocardial protection, high probability of damage to the grafts, the limited space on the aorta (Fig.2).

Hospital mortality (n-2) among these patients was higher than in the group with combined operation (CABG and AVR) and was $18.2 \%$ versus $5.9 \%$ $(\mathrm{p}>0.05) .1$ patient died as a result of myocardial infarction due to injury IMA, and the second cause of death was cerebrovascular accident.

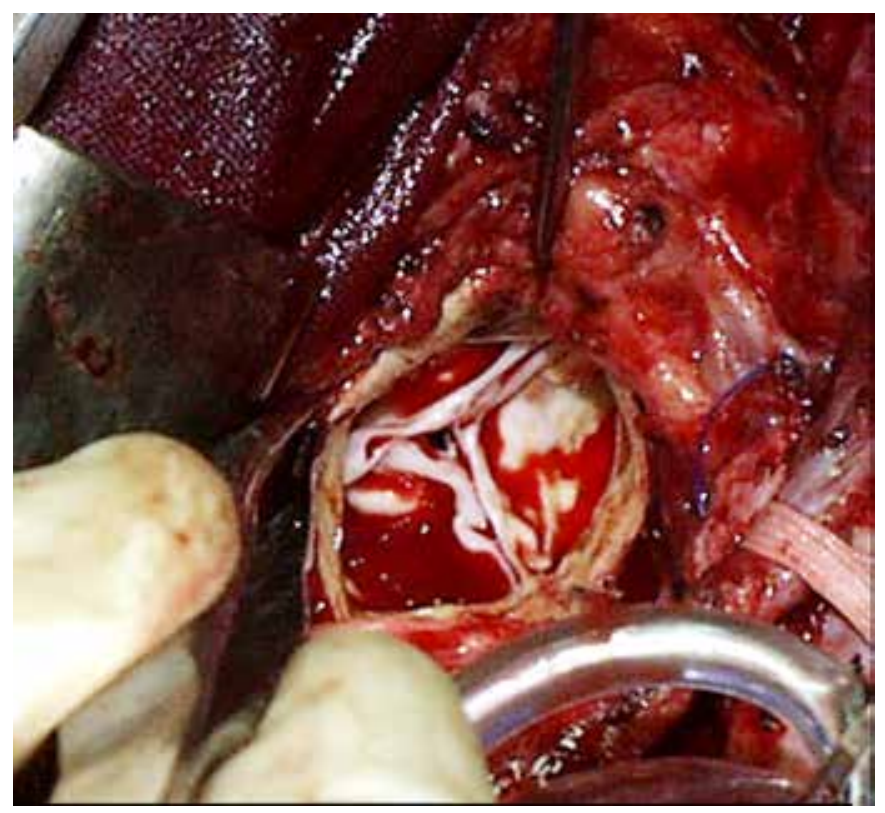

Figure 1. Aortic valve at re-operation

\section{Conclusion}

These data observations suggest that mild, asymptomatic valve deformity may progress to symptomatic, hemodynamically severe AS within a short time after CABG surgery, well before recurrent symptoms of coronary obstructive disease. The analysis of our results in comparison with other studies shows that a moderate stenosis of the aortic valve leaflets with calcification and mean pressure gradient within $25-40 \mathrm{~mm} \mathrm{Hg}$ is sufficient reason for the audit of the aortic valve and combined operations. Execution only isolated coronary artery bypass grafting determines the greater likelihood of re-operation because of the inevitable progression of aortic valve calcification.

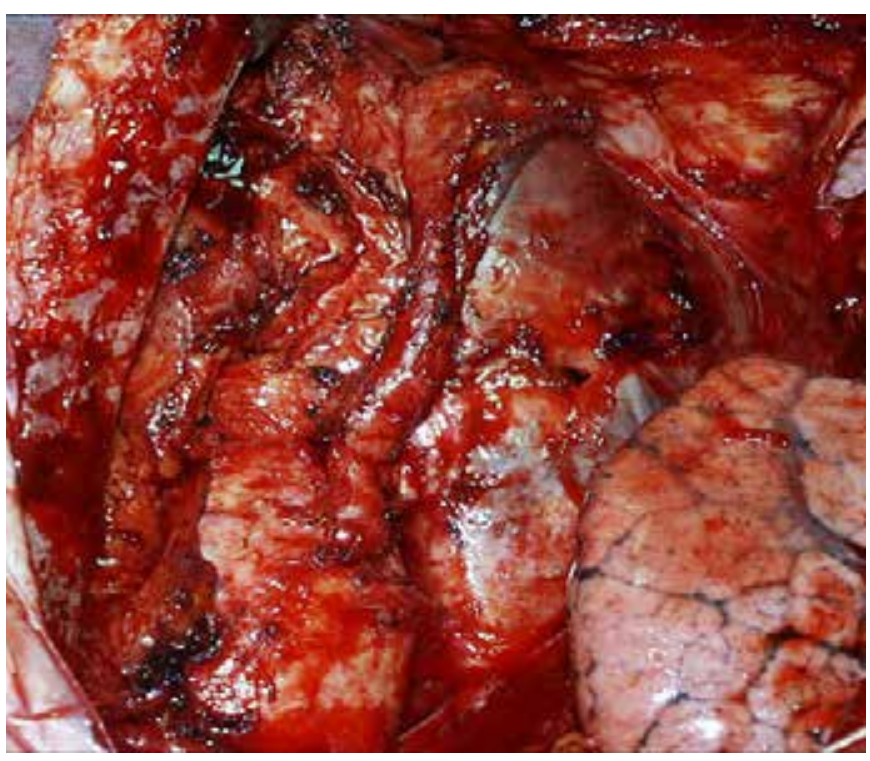

Figure 2. The heart and ascending aorta with re-operation 


\section{References}

1. Alsir A.M. Ahmed, Alastair N.J. Graham, Deirdre Lovell, Hugh O. O'Kane Management of mild to moderate aortic valve disease during coronary artery bypass grafting. Eur J Cardiothorac Surg 2003; 24: 535-540.

2. Collins JJ Jr, Aranki SF. Management of mild aortic stenosis during coronary artery bypass graft surgery. J Cardiac Surg 1994:9 (Suppl):145-7.

3. Davies S.W., Gershlick A.H., Balcon R. Progression of valvar aortic stenosis: a long-term retrospective study. Eur Heart J 1991; 12(1): 10-14.
4. Jacob P. Dal-Bianco, MD. Management of Asymptomatic Severe Aortic Stenosis J Am Coll Cardiol, 2008; 52: 1279-1292.

5. James W. Tam, MDa, Roy G. Masters, MDa, Ian G. Burwash, MDa, Alain D. Mayhew, BSa, Kwan-Leung Chan, MD. Management of Patients With Mild Aortic Stenosis Undergoing Coronary Artery Bypass Grafting. Ann Thorac Surg 1998;65:1215-1219

6. T. Mihaljevic, M. R. Sayeed, S. C. Stamou, and S. Paul. Pathophysiology of aortic valve disease. Card. Surg. Adult, 2008; 3 (2008): 825 - 840.

Received: 27/01/2014

Accepted: 06/05/2014

Published: 20/05/2014

Disclosure and conflicts of interest:

Conflicts of interest were not reported.

Corresponding author:

Dr. Anatoly Molochkov

amolochkov@gmail.com 